\title{
Acervos orais, acervos virtuais: museus, pessoas e histórias de vida
}

\author{
Leticia Bauer*
}

No dia 31 de maio de 2011, começou a circular na internet uma campanha da Intel voltada para usuários do Facebook, rede social virtual que contava, de acordo com as estimativas mais ponderadas na internet, com cerca de 600 milhões de usuários no mundo até o início de 2011. A campanha Museum of Me, criada para promover a segunda geração de processadores i $5,{ }^{1}$ propôs, por meio de um aplicativo acionado pelo interessado, a criação de um museu virtual com base em informações, imagens e vídeos postados no Facebook de cada um dos usuários. A mostra individual pode ser visitada por outras pessoas que fazem parte da rede social e, por meio de museografia virtual, dispõe informaçóes em paredes virtuais, visitadas por pessoas em 3D. Tudo isso centralizado na figura do usuário que tem, no painel de abertura, seu nome pixelizado em letras generosas. Por meio do hiperlink Museum of $\mathrm{Me}^{2}$ é possível visualizar o vídeo promocional.

Milhares de museus biográficos inauguraram e fecharam suas exposições com a rapidez de um clique. No site do Museum of Me, 605 mil pessoas registraram sua aprovação e, ao que tudo indica, criaram suas exposições virtuais individuais. Se este número é pequeno perto de outros fenômenos da internet, revelados para 8 ou 9 milhões de acessos, a realidade museológica brasileira indica cifras bem menores de visitação. E, arrisco dizer, isto se deve

\footnotetext{
* Doutoranda no Programa de Pós-Graduação em História da Universidade Federal do Rio Grande do Sul (UFRGS). Bolsista CNPq.

1 Informação disponível em http://ccsp.com.br/ultimas/noticia.php?id=52745. Acesso em 21/06/2011.

2 Ver http://www.youtube.com/watch?v=qfd54nYPhXk.
} 
menos ao fato de que as exposições físicas requerem deslocamento e mais ao prazer do protagonismo individual. Todas as informações, e isto é importante ressaltar, já estavam virtualmente disponíveis, e um aplicativo "simplesmente" reuniu fotos, palavras e vídeos em outro espaço.

Dois aspectos me impressionaram nessa experiência. Primeiro, o fato de que o ambiente museológico foi utilizado como meio para atrair consumidores. Trata-se de uma exposição contemporânea, visitada virtualmente com o acompanhamento de uma trilha sonora acertada e pouco pretensiosa. Entretanto, ao visualizar duas ou três exposições (várias foram disponibilizadas no YouTube para ampla apreciação ${ }^{3}$ ), tem início a sensação de algo artificial, repetitivo, mecânico, pois todas as exposições são idênticas e o percurso é sempre o mesmo. Em segundo lugar, no final da visita virtual a este museu "pessoal", surgem robôs selecionando fotos que, progressivamente reunidas, formam uma imagem em grandes proporções do usuário. Tal imagem aprofunda-se na tela e forma um ponto que se conecta a um número infinito de outros pontos (outras vidas) que formam uma cadeia - milhares de histórias de vida, lembranças e registros para ver a si mesmo musealizado; milhares de histórias de vida, lembranças e registros usados para vender processadores.

Essa experiência chamou a minha atenção por seu aporte eminentemente virtual: desde os "objetos da exposição", todos produzidos por câmeras digitais, scanners e câmeras de vídeo, até a visita a um museu inexistente fisicamente. Será que temos problematizado suficientemente estas circunstâncias produzidas pelas tecnologias, para além de nos utilizarmos delas?

Historiadores não têm por hábito falar de tecnologias, a não ser das que revolucionaram vidas passadas. Entretanto, as práticas atuais dependem cada vez mais das condições tecnológicas, dos acessos, dos scanners e pixels que estão formando, progressivamente, os acervos de arquivos e museus. Não é o YouTube um gigantesco arquivo de vídeos? Um número infindável de documentos para a história do tempo presente?

3 Ver em http://www.youtube.com/results? search_query=museum + of + me\&aq $=0$. 
As avaliações acerca da tecnologia geralmente provocam prognósticos pessimistas. A superficialidade desponta como vilã nada desprezível. Excesso de informação versus falta de profundidade. Ao que tudo indica, o "raciocínio dos hiperlinks" não é passageiro e e-books estão ganhando adeptos. A recente publicação A questão dos livros: passado, presente e futuro, reunião de artigos de Robert Darnton lançada em 2010, aborda questóes sobre os livros na era digital e discute as possibilidades da digitalização dos acervos de grandes bibliotecas, democratizando o acesso universal aos usuários. O livro, que por tanto tempo habitou bolsas, mochilas e prateleiras, é agora duplicado e distribuído com a rapidez possibilitada por uma boa conexão, gerando um número incalculável de múltiplos. Direitos autorais lesados, direitos autorais problematizados. ${ }^{4}$ Roger Chartier (2002, p. 31), que também se dedicou ao tema, destaca: "a tela não é uma página, mas sim um espaço de três dimensões que possui profundidade e que nele os textos brotam sucessivamente do fundo da tela para alcançar a superfície iluminada. [...] no espaço digital, é o próprio texto, e não seu suporte, que está dobrado". Livros têm índice. Um site, não por acaso, tem um mapa. Uma chance de não nos perdermos para sempre na cadeia de hiperlinks.

Por outro lado, já estamos habituados a textos feitos na e para a tela de computador. A Revista História Oral, por exemplo, deixou de ser impressa para ter sua versão unicamente digital. Pode ser impressa? Pode, mas não necessariamente. Nossos olhos agora percorrem as barras de rolagem, nosso dedo indicador acessa o hiperlink por meio de um mouse que, para além de uma alternativa facilitadora, imprime ao conhecimento a possibilidade de cadeias infinitas de relações cuja linearidade inexiste. E a prática do historiador diante disso? Difícil precisar. Segundo Chartier, o que se coloca de imediato em face da textualidade eletrônica é a articulação aberta, fragmentada e relacional permitida pelos hipertextos. Mais que isso, as "provas" fornecidas pelos historiadores por meio de rodapés, citaçóes e referências podem ser consultadas pelo leitor. É possível acompanhar o percurso da pesquisa e refazê-lo, parcial ou totalmente, na medida em que podem ser disponibilizados documentos, imagens, registros de áudio e vídeo que foram utilizados para a produção de determinado conhecimento (Chartier, 2010, p. 59-60).

4 Diversos autores apontam para a necessidade de redefinição de categorias jurídicas, estéticas, administrativas e biblioteconômicas que foram pensadas e construídas em função do livro impresso e que não se aplicam, necessariamente, ao universo eletrônico (Chartier, 2002, p. 117). 
História oral e tecnologia são antigas conhecidas. Gravadores de fita cassete e filmadoras, variáveis em modelo e tecnologia, fazem parte do estojo obrigatório do pesquisador. Os produtos deste trabalho formam acervos compostos por gravações em áudio, vídeo e transcrições que passam a habitar prateleiras, caixas e armários. Conformam arquivos específicos, vozes que se entrecruzam em dissertações e teses, por meio de citações de trechos selecionados, mas que, quando guardados, são separados em seu absoluto de horas de perguntas, respostas, silêncios e barulhos de cozinha. Podemos não falar de tecnologias, mas dependemos dela inexoravelmente para acessar essas falas. Precisamos da mediação de máquinas que nos revelam, quando acionadas, o tempo exato de um silêncio, o tom da voz, as nuances de uma resposta evasiva.

Proponho apresentar neste artigo uma experiência que considero capital para discutir algumas das possibilidades da tríade história oral, memória e novas tecnologias. Trata-se do Museu da Pessoa, ${ }^{5}$ uma instituição sem fins lucrativos fundada na cidade de São Paulo, em 1991, com o objetivo de construir uma rede internacional de histórias de vida. Devido à tipologia desta instituição, a discussão proposta ocorrerá sempre nas proximidades da esfera do patrimônio cultural e, mais especificamente, dos museus. Se, por um lado, isso pode ser um pouco frustrante em função da restrição, por outro, certas especificidades são capazes de ser instigantes. Além disto, entre as variadas novas tecnologias, o virtual será privilegiado, entendido como aquilo que pode vir a ser, mas que não precisa existir, necessariamente, em sua materialidade física (Henriques, 2004, f. 10). A noção de memória será compreendida a partir de Halbwachs $(1990)$ e Pollak $(1989,1992)$ tendo em vista a proposta da instituição museológica escolhida. No Museu da Pessoa, o conceito de memória é compreendido a partir de seu caráter social, de partilha entre indivíduos e grupos.

O Museu da Pessoa define-se como um museu virtual ${ }^{6}$ e busca atuar na preservação dessas histórias em base digital, e seu acervo, com mais de 20 mil registros, é constituído, eminentemente, por relatos orais. ${ }^{7}$ Ao longo de

5 Ver http://www.museudapessoa.net/index.shtml\#.TgjGu2Fa-nA.

6 Segundo a pesquisadora Rosali Henriques (2004, f. 67), um museu virtual difere de um cibermuseu, na medida em que estes últimos são reproduções online do acervo ou parte do acervo físico, e os museus virtuais possuem ações museológicas, ou parte delas, realizadas em um espaço virtual.

7 O Museu da Pessoa baseia-se em metodologias desenvolvidas a partir das técnicas da história oral, de acordo com o estabelecido por Karen Worcman e Jesus Vasquez Pereira (2006). 
15 anos de existência, o Museu da Pessoa realizou cerca de 100 projetos de memória, seis CDs, 26 livros, 24 documentários, 40 exposições, e desenvolveu sete centros de memória e 13 intranets e sites temáticos. $\mathrm{O}$ acervo foi construído a partir dos projetos desenvolvidos pela equipe do Museu, muitas vezes em parceria com outras instituições, e por meio do recebimento de histórias pela internet (Worcman, [s.d.], p. 7). Os projetos foram o início da proposta e basearam-se na captação, no processamento e na edição das histórias de vida de pessoas ligadas a um dado segmento social, grupo ou instituição (Worcman, [s.d.], p. 5). No portal do Museu figura um código de conduta ${ }^{8}$ que estabelece alguns parâmetros para a inserção e para o uso de depoimentos.

De acordo com o texto disponível no portal, "A missão do Museu da Pessoa é contribuir para tornar a história de cada pessoa valorizada pela sociedade. Visamos a um mundo mais justo e democrático baseado na história de pessoas de todos os segmentos da sociedade". Por meio dos valores apresentados no portal, ${ }^{10}$ é possível perceber a ênfase dada ao protagonismo histórico e à democratização da participação dos indivíduos na construção da memória social como forma, inclusive, de empoderamento, visando à mudança de condições sociais.

Por definir-se como virtual, o Museu da Pessoa insere-se em uma categoria que figura entre uma gama generosa de definições, como museu eletrônico, museu digital, museu online, museu hipermídia, meta-museu, museu cibernético, cibermuseu e museu no ciberespaço (Henriques, 2004. f. 9). Bastam todas estas definições para percebermos que as categorias da virtualidade ocupam um espaço onde, na maioria das vezes, a relação com o que já conhecemos e estudamos ultrapassa a simples correspondência entre físico e virtual:

A Internet possibilitou transformar átomos em bits. Ou seja, matéria palpável (objetos) em código binário. Nesse sentido, os museus passam a trabalhar com referências patrimoniais digitais na Internet. E, portanto, passíveis de serem trabalhadas de várias formas. Além disso, a Internet possibilitou aos museus interagirem de forma globalizada, alterando a noção de tempo e de espaço. Ou seja, o museu na Internet nunca fecha. (Henriques, 2004, f. 2).

\footnotetext{
8 Ver http://www.museudapessoa.net/facaparte/codigo_de_conduta.shtml.

9 Ver http://museudapessoa.net/oquee/oque_nossacausa.shtml.

10 Ver http://museudapessoa.net/oquee/oque_nossacausa.shtml.
} 
A partir dos pressupostos acima elencados, o Museu da Pessoa configura um interessante cruzamento: baseia-se nas proposições e nas metodologias da história oral, aposta na memória como fator primordial nos relatos e interage com o público por meio de uma base virtual disponível na internet. Parte-se do pressuposto de que a virtualidade não é uma forma alternativa ao espaço físico do Museu, mas seu fator constitutivo por excelência, e soma-se a esta assertiva sua caracterização como instituição museológica e não arquivística. Pretendo tratar de duas questôes neste artigo. A primeira refere-se à forma deste acervo e o que suponho ser uma especificidade que tangencia as práticas correntes em museus e arquivos no que diz respeito ao seu uso e preservação. A segunda refere-se aos depoimentos, especialmente os enviados para o Museu através do portal por pessoas que não fazem parte de projetos desenvolvidos pela instituição.

II

No Museu da Pessoa, como já foi dito anteriormente, a virtualidade é intrínseca ao entendimento do acervo e suas formas de preservação, e isto não implica, necessariamente, o uso da internet. De acordo com as informações disponibilizadas sobre a trajetória do Museu no portal, ${ }^{11}$ a proposta de preservar histórias de vida organizadas em base digital, como CDs, por exemplo, antecedeu a utilização da internet. Foi somente em 1996 que ocorreu a criação de um site do Museu da Pessoa. A imaterialidade dos depoimentos provocou, desde o início, uma reflexão sobre as formas de concentração, captação e difusão do acervo:

Narrativas são objetos intangíveis por sua própria natureza. Não cabia ao Museu da Pessoa transformá-las em objetos tridimensionais - i.e. ter como foco apenas a preservação dos suportes -, nem mesmo concentrá-las em um dado "espaço". Nossa primeira conclusão foi a de que esta sede deveria ser virtual: uma base de dados organizada de forma a permitir amplo uso pela equipe do Museu da Pessoa assim como pelo público. Nossa tarefa era identificar as mais diversas oportunidades de captação e uso dessas histórias.

11 Ver http://www.museudapessoa.net/oquee/oque_nossahistoria.shtml. 
Sua difusão em rede foi, desde o princípio, nossa opção. O “acervo", neste sentido, não poderia ser físico. $\mathrm{O}$ suporte deveria ser digital e a forma de disponibilizar o conteúdo a mais ampla possível. Assim, os primeiros conteúdos produzidos pelo Museu da Pessoa tornaram-se um conjunto de CD-Roms temáticos distribuídos aos públicos e dispostos em quiosques multimídias. (Worcman, [s.d.], p. 2).

Como preservar estes registros que, para além de seu suporte físico, são caracterizados pela oralidade? Primeiramente, relativiza-se a noção de objeto: "não basta transformar o objeto em algo puramente simbólico e intangível, é necessário também rever o conceito de preservação como algo distinto da prática cuidadosa de selecionar, catalogar e cuidar da perenização de um dado objeto de coleção" (Worcman, [s.d], p. 3). Segundo Lévy (2000, p. 202), o museu como valor é questionado no ciberespaço, na medida em que "as distinções entre original e cópia já não têm evidentemente razão de ser". Estas duas afirmações, quando relacionadas ao mundo virtual, colocam em questão o uso como forma de preservação e a noção de cópia como forma válida de acervo.

O acervo do Museu da Pessoa não desgasta, não é afetado pela luz, não impõe restrição ao número de visitantes. Os suportes, como CDs ou DVDs, devem ser conservados em sua integridade física, mas os depoimentos no portal permanecem inacessíveis ao desgaste do tempo, sejam vídeos, áudios ou transcrições. Neste ponto, o fantasma da obsolescência tecnológica entra em cena e faz com que sempre se questione a validade da substituição de formas conhecidas de armazenamento por opções baseadas em mídias digitais contemporâneas. Este debate aumenta graças a políticas equivocadas de descarte, nas quais os suportes físicos são eliminados e suas imagens copiadas para CDs que não abrem mais. Mas não estamos tratando da formação de imagens de documentos, e enfatizo aqui a ideia da imagem, cujos impressos foram descartados. Estamos tratando de documentos produzidos em formas digitais, por meio de gravações de áudio e vídeo. O mal do backup talvez seja uma das ameaças do mundo moderno e, também, sua salvação temporária.

Parece não ser errôneo afirmar que este tipo de acervo, formado por depoimentos orais gravados, ocupa uma instância variável em relação aos objetos museológicos aos quais estamos habituados. Um objeto tridimensional é observado e, a partir de seus materiais, marcas, formas e desgastes, são possíveis inferências em seu uso e sua época. Esta investigação, que se processa de 
maneira muito breve, na maioria dos casos não se aplica às mídias digitais. $\mathrm{Na}$ nossa frente temos, em princípio, somente um CD ou um HD externo. No caso de objetos bidimensionais - tomemos como exemplo uma carta uma segunda forma de conhecimento é procedida. Buscamos compreender a grafia, o idioma, decodificar as letras, formar palavras, ordenar a leitura. Esse processo tem uma ordem inteligível, que é a da narrativa escrita, e depende desse entendimento para tornar-se um enigma passível de solução. Mídias digitais são uma terceira possibilidade. Dependemos de uma máquina para compreender, precisamos de um leitor (cujo trocadilho poderia fornecer boas comparações). Pode ser um gravador, um aparelho de DVD, um computador. Se o conteúdo é apresentado de maneira conhecida quando lido pela máquina - identificamos uma pessoa falando - a forma não nos diz absolutamente nada. Evidente que objetos físicos, sejam eles bidimensionais ou tridimensionais, remetem a um significado extrínseco a sua materialidade e não falam por si. Porém, registros digitais nos fazem depender de um elemento a mais, o decodificador do suporte.

O Museu da Pessoa alia práticas de preservação tradicionalmente utilizadas em museus e arquivos (cópia de fitas, manutenção em acervo climatizado), mas o processo de preservação equilibra-se entre um suporte que não comunica e a necessidade imperiosa de sua existência como meio. Segundo Worcman ([s.d.], p. 4),

Nosso grande desafio de preservação é [...] identificar e estimular o uso contínuo e ampliado do acervo de histórias de vida, pois na medida em que essas histórias estiverem presentes em publicações, rádios, TVs e salas de aula, estaremos garantindo sua preservação, não somente pela perenização de seus suportes, mas, sobretudo, pelo processo de uso e reuso de seus conteúdos.

A partir disso, é possível compreender o limite tênue desse acervo como bem cultural e como documento, como referente cultural e como fonte. Mais que isso, como múltiplo. A cópia como forma de acervo é tida, na preservação de bens culturais materiais, como uma alternativa para que não ocorra o desgaste do "original". A noção de autenticidade é tão cara aos técnicos de museus e instituições de preservação do patrimônio cultural que a ideia de imagem como forma de conhecimento e apreensão fica obscurecida, para não dizer anulada. Llorenç Prats (1997, p. 65) assinalou esse paradoxo de forma 
espirituosa: "Yo ignoro si la Gioconda que se expone en el Louvre es el original o una esmerada copia, pero sí hay dos cosas que me atrevo a afirmar con razonable convicción: que el conocimiento artístico que se transmite es el mismo y que las colas para contemplarla no se formarían si se tuviese la certeza de que se trataba de una copia."

Mas qual é o "original” de uma gravação? A mídia que foi usada para registro na hora e no local da entrevista? Mídias digitais supóem reprodução e, muitas vezes, é isso que garante sua existência. O conteúdo de fitas cassete já foi gravado em disquete, passado para CD, duplicado para DVD, armazenado em HDs ou em fitas DAT, transformado em arquivos para programas de áudio para ser ouvido no computador ou carregado em pendrive e, apesar de tudo isso, arrisco, nunca se levantou a questão da originalidade. Os documentos orais pertencem à outra ordem, à ordem do múltiplo. Disponibilizálos em um museu virtual significa estender o múltiplo em sua reprodução ilimitada.

III

No Museu da Pessoa a memória é compreendia em seu caráter social e identitário a partir de referências como Michael Pollak e Maurice Halbwachs, conforme foi explicitado anteriormente, além de vários outros autores que convergem para a percepção da multiplicidade e da seletividade dos processos associados à memória. Soma-se a isto a compreensão de que o interesse pelas histórias de vida não se relaciona com a busca de informações propriamente ditas, mas com a forma de articulação de uma narrativa, afastando os depoimentos de uma realidade histórica presumida em sua existência. O que se registra é o olhar do presente sobre o passado. Uma "história conta muito mais de seu narrador do que dos fatos por ele lembrados" (Worcman, [s.d.], p. 4). Essa proposta distende a percepção acerca das flutuações da memória. O Museu realiza pesquisas históricas, localiza seus depoentes, associa documentos à narrativa. Ao tratar da relação entre tempo e vida, Worcman ([s.d.], p. 22) esclarece parte da proposta do Museu para essa articulação:

Cada uma dessas histórias apresenta visões subjetivas e pessoais da realidade. Mas todas reagem a um tempo histórico comum, a uma mesma realidade social, ainda que vista e interpretada de forma diversa por cada um. 
Não escapamos aos processos históricos. Somos deles resultado ao mesmo tempo em que somos agentes de sua transformação. Todos desenvolvemos estratégias de sobrevivência que respondem a demandas comuns. No entanto, não há empatia se não nos identificamos com o outro. As histórias de vida têm o poder de provocar essa potencial identificação entre pessoas, por mais diversas que sejam.

Entretanto, parece-me difícil - e talvez até inoperante - articular, obrigatoriamente, um contexto histórico ligado aos marcos que estamos tão familiarizados por meio de manuais de história com um depoimento sobre a infância no Bairro do Brás, por exemplo. Contextualizações nem sempre são determinantes, nem sempre ajudam a entender o que ambicionamos, e admitir isto, mais do que uma praxe de historiadores, problematiza de forma um tanto contundente a relação entre a narrativa histórica e os depoimentos espontâneos que mencionarei logo a seguir. É a partir da relação entre histórias de vida e histórias de grupos que o Museu da Pessoa traça sua atuação:

Se cada uma das histórias é peça única de nosso acervo, é na articulação entre as narrativas que podemos vislumbrar diversas perspectivas da História. Neste sentido, nosso partido foi o de trabalhar para permitir ao público as mais variadas leituras desse acervo. Assim, tanto a captação quanto a conexão entre os depoimentos vêm sendo pensadas de forma que a "curadoria" seja compartilhada entre nós e o público. (Worcman, [s.d.], p. 3).

Essa curadoria merece atenção. Por meio da agilidade de um sistema de busca no portal, é possível realizar as mais diferentes seleções de depoimentos. É possível realizar pesquisas por qualquer palavra, nome do depoente, seu perfil, imagens, áudios e vídeos. Gostaria de chamar a atenção para duas opções: a busca por qualquer palavra e a busca por meio do perfil do depoente. No primeiro caso, é possível a localização por temáticas. Ao digitar a palavra "infância", por exemplo, tem-se acesso a todos os depoimentos disponíveis em que esta expressão foi empregada. Na segunda opção, critérios são utilizados pelo usuário para a definição do perfil do depoente por meio das categorias sexo, data de nascimento, período de nascimento, local, profissão, situação migratória (se migrante ou imigrante) e projeto desenvolvido pela equipe do Museu. Todas estas definições recortam um objeto de busca, acessam locais e histórias com as quais não seria possível ter contato. Ambas as formas de busca reúnem personagens que talvez nunca fossem agrupados. 
Em 1997 foi criado um programa que considero relevante para a discussão. Trata-se da seção "Conte sua história", disponível na abertura do portal em sua configuração atual. Por meio desta alternativa, qualquer pessoa pode enviar sua história, acompanhada de outros documentos que julgue relevantes para sua narrativa. É possível também escrever a própria história de vida e enviar ao Museu por meio do formulário disponível no portal ou agendar uma ida à sede institucional para gravar a entrevista em cabines especiais para tal fim. Estas duas alternativas são disponibilizadas independentemente da participação do interessado em algum projeto desenvolvido. ${ }^{12}$

O que ocorre no processo de narrativa do "Conte sua história" é que a figura do entrevistador é eliminada. Suprime-se a possibilidade de intervenção, de condução e de retomada. Mais que isso, torna-se inacessível, porque inexistente, a baliza proporcionada pelas perguntas do entrevistador. A partir das perguntas percebemos os desvios, as "desconversas", as derivações. Por meio do depoimento sem entrevistador, dependemos exclusivamente do narrador. A ele é dado o poder de condução e narração, e esse documento não é produzido de forma compartilhada, como nos acostumamos a tratar o resultado de entrevistas. Com um clique, a história, narrada ou gravada, separa-se do depoente para, se as conexões permitirem, chegar ao Museu da Pessoa. Se tudo correr bem, será disponibilizado para o acesso de todos. Em quais outras circunstâncias isto seria possível?

\section{Referências}

CHARTIER, R. Os desafios da escrita. São Paulo: Editora Unesp, 2002. . A história ou a leitura do tempo. Belo Horizonte: Autêntica Editora, 2010.

DARNTON, R. A questão dos livros: passado, presente e futuro. São Paulo: Companhia das Letras, 2010.

HALBWACHS, M. A memória coletiva. São Paulo: Vértice, 1990.

12 Estes projetos, aliás, configuram um capítulo extenso na trajetória do Museu e não tratarei deles de forma mais detida neste artigo. De qualquer maneira, é importante ressaltar que o Museu da Pessoa capacita pessoas para realizarem entrevistas. Mais informaçóes sobre os projetos encontram-se em http://www. museudapessoa.net/oquee/oque_programas_formacao.shtml. 
HENRIQUES, R. M. N. Memória, museologia e virtualidade: um estudo sobre o Museu da Pessoa. Dissertação (Mestrado em Museologia)-Universidade Lusófona de Humanidades e Tecnologias, Lisboa, 2004.

LÉVY, P. Cibercultura. Lisboa: Instituto Piaget, 2000.

POLLAK, M. Memória, silêncio e esquecimento. Estudos Históricos, Rio de Janeiro, v. 2, n. 3, p. 3-15, 1989.

POLLAK, M. Memória e identidade social. Estudos Históricos, Rio de Janeiro, v. 5, n. 10, p. 200-212, 1992.

PRATS, L. Antropología y patrimonio. Barcelona: Ariel, 1997.

WORCMAN, K. Como histórias de vida mostram cidades invisiveis. [s.d.]. Disponível em: <http://www.museudapessoa.net/blogs/memorias/karen_artigo_coreia_portugues.pdf >. Acesso em: 21 jun. 2011.

WORCMAN, K.; PEREIRA, J. V. (Coord.). História falada: memória, rede e mudança social. São Paulo: SESC SP; Museu da Pessoa; Imprensa Oficial do Estado de São Paulo, 2006.

Resumo: Este artigo pretende discutir as relações entre oralidade, mídias digitais e virtualidade a partir da perspectiva da formação e do uso de acervos produzidos pela história oral. Será privilegiada para análise a experiência do Museu da Pessoa, um museu virtual de histórias de vida fundado na cidade de São Paulo em 1991. Por meio da trajetória do Museu é possível identificar um interessante cruzamento entre história oral - como meio para a formação de acervo, memória e pressuposto fundamental de sua existência - e tecnologia, na medida em que sua ação se desenvolve na virtualidade.

Palavras-chave: Museu da Pessoa, acervos museológicos, oralidade, tecnologia.

\title{
Oral collections, virtual collections: museums, persons and stories of lives
}

\begin{abstract}
This paper discusses the relationship between orality, digital medias and virtuality, taking as perspective the formation and use of collections produced by oral history. Emphasis will be given to the analysis of the experience of The Museum of the Person, virtual museum about stories of lives, based in São Paulo since 1991. Through the course of the Museum, it is possible to identify an interesting crossing among oral history - as a means of collections formation, memory and fundamental assumption of its existence - and technology, as its action is developed in virtuality.
\end{abstract}

Keywords: The Museum of the Person, museum collections, orality, tecnology.

Recebido em 02/07/2011

Aprovado em 15/08/2011 